\title{
Prevalence of multidrug resistance in the Egyptian methicillin-resistant Staphylococcus
} aureus isolates

Eman S.H. Ibrahim ${ }^{1}$, Khaled Z. El-Baghdady², Said M. Abd El-All', Mohamed A.A. Warda ${ }^{3}$, Abdelbary M. Prince ${ }^{3}$ and Mohamed K. Ibrahim ${ }^{2 *}$ 1- National Organization for Drug Control and Research, Giza, Egypt.

2- Department of Microbiology, Faculty Science, Ain Shams Univ., Cairo, Egypt. 3- Department of Biochemistry, Faculty of Veterinary Medicine, Cairo Univ., Giza, Egypt.

* Corresponding author Email: khaledsaa@yahoo.co.uk

Received: Feb. 10, 2020; Accepted: Mar. 21, 2020; Available online : April 5, 2020

\begin{abstract}
Methicillin-resistant Staphylococcus aureus (MRSA) is one of the major health hazards and became of greater public health concern. This work aimed to shed substantial light on prevalence of MRSA in different clinical isolates and their resistance to different antibiotics. Among 258 Staphylococcus aureus isolates recovered from different clinical sources (urine, pus, throat swab, blood, seminal fluid, prostatic fluid, sputum swab, ascetic fluid, skin swab, nipple discharge and urinary catheter). 70 isolates were identified as MRSA. The highest percentage of MRSA was recorded from pus samples $(57.1 \%)$ followed by urine (30\%). Antimicrobial susceptibility test using 14 antibiotics showed that all MRSA were resistant to amoxicillin and cefuroxime, while only $50 \%$ were sensitive to vancomycin. High minimum inhibitory concentration of oxacillin $(256 \mu \mathrm{g} / \mathrm{ml})$ was detected in $12.9 \%$ of MRSA isolates.
\end{abstract}

Keywords: Staphylococcus aureus, MRSA, Oxacillin, ORSAB, Clinical.

\section{INTRODUCTION}

Staphylococci are opportunistic human pathogen capable of causing a wide variety of diseases (Moorem and Lindsay, 2001; Boyd and Brüssow, 2002). Most people are passive carrier of staphylococci (Kluytmans et al., 1997), and in some cases, an infection may arise from selfinoculation of a wound. Staphylococcal infections have been a major problem in hospitals for decades, but the incidence of community-acquired infections has also been increasing (Chambers, 2001). Staphylococcus aureus (S. aureus) is a bacterium that belongs to the family of staphylococcaceae forming part of the normal flora of skin, intestine, upper respiratory tract and vagina (Lowy, 1998). $S$. aureus can become pathogenic when conditions such as $\mathrm{pH}$, temperature and nutrient availability are altered and become favorable for overgrowth (Mims et al.,
2004). Historically, S. aureus has been recognized as an important cause of disease around the world and has become a major pathogen associated with both hospital and community-acquired infections (Panlilio et al., 1992; Tong et al., 2015; Lake et al., 2018).

Before the availability of antibiotics, invasive infections caused by $S$. aureus were often fatal. The introduction of penicillin greatly improved the prognosis for patients with severe staphylococcal infections, but after a few years of clinical use resistance appeared in $S$. aureus due to production of betalactamases. Methicillin was designed to resist hydrolysis by beta-lactamases, but soon after methicillin was introduced into clinical practice, resistant $S$. aureus strains were identified and designated as Methicillin-resistant Staphylococcus aureus (MRSA). The term MRSA has 
Eman S.H. Ibrahim et al.

been retained, although oxacillin has now replaced methicillin for susceptibility testing in laboratories and is the marker for classifying $S$. aureus as MRSA. Until recently, MRSA was predominantly a nosocomial pathogen causing hospitalacquired as well as community-acquired infections (Mera et al., 2011; Tong et al., 2015; Boswihi and Udo, 2018).

Due to the increase of MRSA strains every decade, these bacteria were identified in the early 1980's as a major cause of nosocomial infections (Boyce et al., 2004). The possibility of transmission of healthcare associated MRSA (HAMRSA) to the community was obvious. Since 1987, MRSA was increasingly found in the community associated-methicillinresistant $S$. aureus (CA-MRSA) presented with severe skin and soft tissue infections as well as necrotizing pneumonia (Hayani et al., 2008).

MRSA infections account for one fifth of all hospital-acquired infections, costing the UK National Health Service approximately $£ 1$ billion per year (Cepeda et al., 2005). The problem has been aggravated by the rapid spread and high incidence of MRSA in intensive-care units (Cepeda et al.,2005). The continuing rise in MRSA infection rates and its spread worldwide has led to calls for action to control infection and develop novel antiMRSA agents and vaccines (Cutler and Wilson, 2004; Hancock, 2007).

The aim of this work was to assess the source of MRSA isolates as well as describe the antimicrobial susceptibility patterns of these isolates.

\section{MATERIALS AND METHODS Clinical isolates}

A total of 379 Gram positive clinical isolates were kindly provided from El-Demerdash hospital in Cairo, Egypt during the period between January 2016 and December 2017. These isolates were recovered from different clinical sources including; urine, pus, throat swab, blood, seminal fluid, prostatic fluid, sputum swab, ascetic fluid, skin swab, nipple discharge and urinary catheter.

\section{Identification of Staphylococcus aureus}

All isolates were purified on nutrient agar (Oxoid. UK Code: CM0003) then preliminary identified by conventional microbiological methods including Gram staining (Isenberg, 1992), morphology and growth on selective media including BairdParker agar medium (Difico) (BairdParker, 1962; Bannerman, 2003), blood agar medium (Oxoid, UK , CM0271) (Murray et al., 1999) and mannitol salt agar medium (Oxoid, UK, CM0085) (Koneman, 1992). All media were incubated at $37^{\circ} \mathrm{C}$ for $48 \mathrm{~h}$. After incubation period, biochemical testes; coagulase and catalase, were carried out according to Bannerman (2003) and Kloos and Schleifer (1986). Colonies that were Gram positive with black, $\beta$-hemolysis and yellow growth on Baird-Parker agar, blood agar and mannitol salt agar media, respectively, with positive coagulase and catalase were identified as $S$. aureus and stored on nutrient agar in $4^{\circ} \mathrm{C}$ for further investigations.

\section{Identification of MRSA isolates}

S. aureus isolates were streak on oxacillin resistance screening agar base medium (ORSAB) (Oxoid, UK, CM1008) and incubated at $37^{\circ} \mathrm{C}$ for $48 \mathrm{~h}$ (CLSI, 2017 and Kluytmans et al., 2002). In addition, they were tested for their susceptibility towards cefoxitin $(30 \mu \mathrm{g})$ and oxacillin $(1 \mu \mathrm{g})$ by disk diffusion as per CLSI (2017). Positive MRSA showed growth on ORSAB and were resistance to both cefoxitin and oxacillin.

\section{Antimicrobial susceptibility test}

Antimicrobial susceptibility of MRSA isolates against 14 antibiotics was carried out using agar disc diffusion method according to CLSI (2017). The antibiotic disks used in this study were purchased from Oxoid, England. The antibiotics used were vancomycin (VA 30 
$\mu \mathrm{g}$ ), amikacin (AK $30 \mu \mathrm{g}$ ), tobramycin ( $\mathrm{Tb} 10 \mu \mathrm{g}$ ), erythromycin (E $15 \mu \mathrm{g}$ ), clarithromycin (CLR $15 \mu \mathrm{g}$ ), amoxicillin (AX $25 \mu \mathrm{g}$ ), clindamycin (DA $2 \mu \mathrm{g}$ ), chloramphenicol (C $30 \mu \mathrm{g}$ ), meropenem (MRP $10 \mu \mathrm{g}$ ), imipenem (IPM $10 \mu \mathrm{g}$ ), cefuroxime (CXM $30 \mu \mathrm{g}$ ), ciprofloxacin (CIP $5 \mu \mathrm{g}$ ), ofloxacin (OFX $5 \mu \mathrm{g}$ ), tetracycline (TE $30 \mu \mathrm{g})$.

Determination of minimum inhibitory concentration (MIC) of oxacillin

The MIC of oxacillin was determined by the well agar diffusion method using plates containing Mueller Hinton agar medium (Oxoid, England) inoculated with MRSA isolates $\left(10^{4}\right.$ CFU/ml) according to NCCLS (2017) and
EUCAST (2000). MIC was defined as the lowest antibiotic concentration that showed no bacterial growth after incubation period.

\section{RESULTS AND DISCUSSIONS Identification of the Staphylococcus aureus isolates}

Among 379 isolates, 258 (68\%) were identified as $S$. aureus. The isolates of $S$. aureus were recovered from different clinical sources including: urine $(40 \%)$, pus $(33.3 \%)$, throat swab $(12.8 \%)$, blood $(3.1 \%)$, seminal fluid $(3.1 \%)$, prostatic fluid $(3.1 \%)$, sputum swab $(1.2 \%)$, ascetic fluid $(0.8 \%)$, skin swab $(1.5 \%)$, nipple discharge $(0.8 \%)$ and urinary catheter $(0.3 \%)$ (Fig. 1).

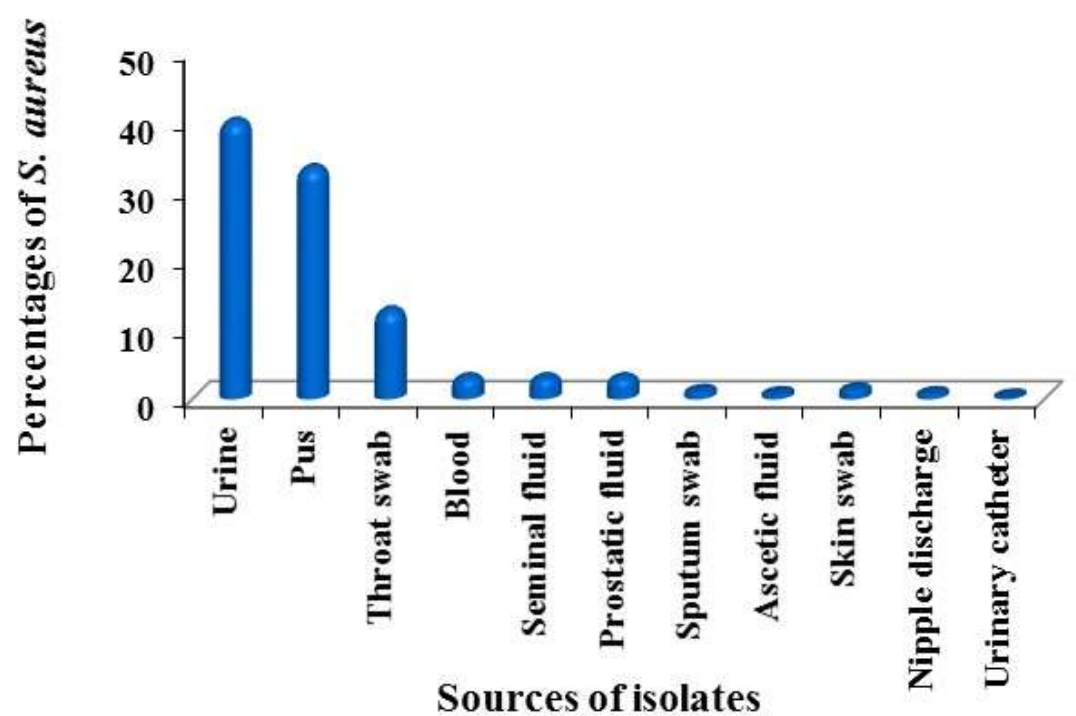

Fig. (1): Percentages of $S$. aureus recovered from different clinical sources.

\section{Phenotypic identification of MRSA}

$S$. aureus isolates were subcultured on ORSAB plates for $48 \mathrm{~h}$ at $37^{\circ} \mathrm{C}$. Among the $258 \mathrm{~S}$. aureus isolates, only 70 were identified as MRSA which gave blue growth on ORSAB agar medium (Fig. 2). Moreover, 70 of these isolates were resistant to cefoxitin $30 \mu \mathrm{g}$ (zone of inhibition $\leq 21)$ and $1 \mu \mathrm{g}$ oxacillin disc (zone of inhibition $\leq 11$ ). 


\section{Eman S.H. Ibrahim et al.}

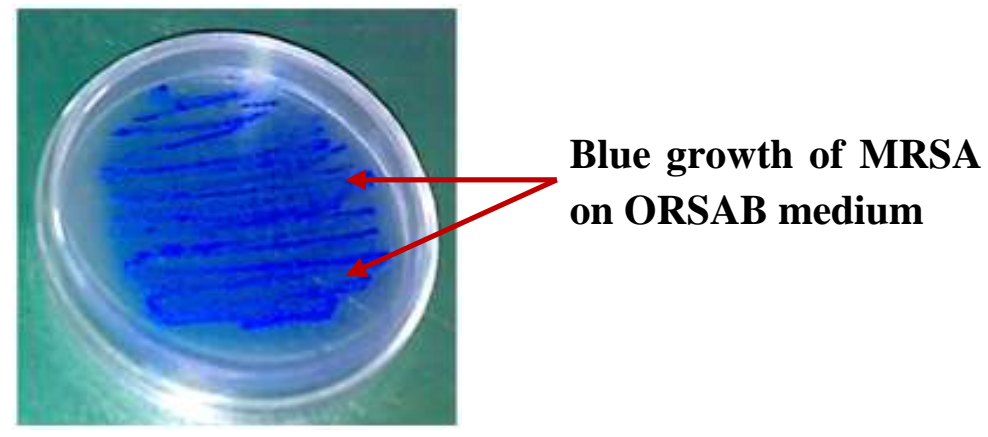

Fig. (2): Methicillin resistant $S$. aureus (MRSA) grown on ORSAB agar medium.

Distribution of MRSA in clinical samples

Higher percentage of MRSA was recovered from pus $(57.1 \%)$ followed by urine $(30 \%)$, skin swab $(5.71 \%)$, throat swab (2.9\%), while1.43\% from blood, urinary catheter, sputum swab collectively. No MRSA isolates were detected in nipple discharge, seminal fluid, prostatic fluid or ascetic fluid (Fig. 3). According to the relation between source of MRSA and gender, higher MRSA isolates were detected in females compared with males except those recovered from pus (male $65 \%$, female 35\%) (Fig. 4).

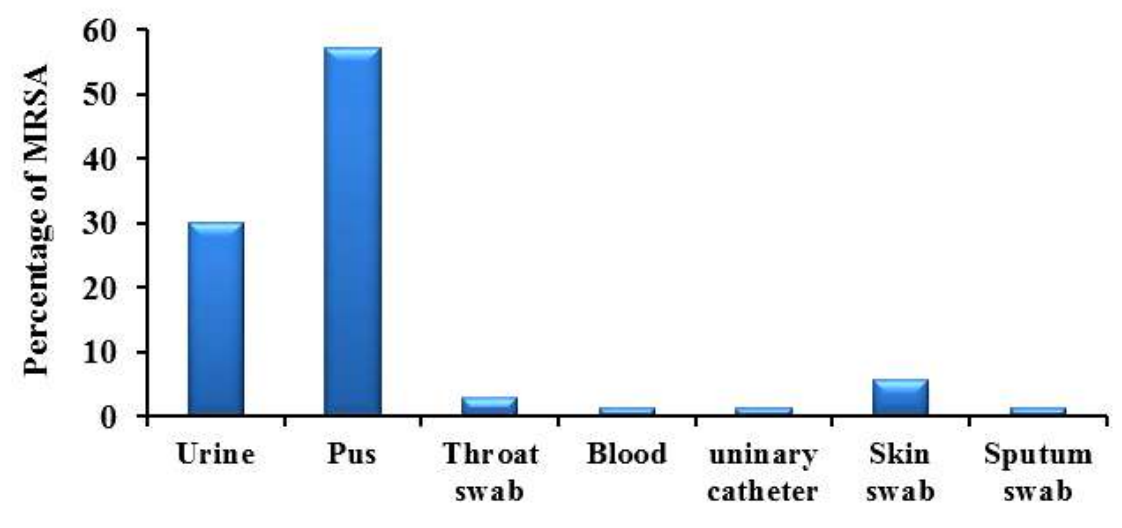

Source of clinical isolates

Fig. (3): Distribution of MRSA in clinical samples.

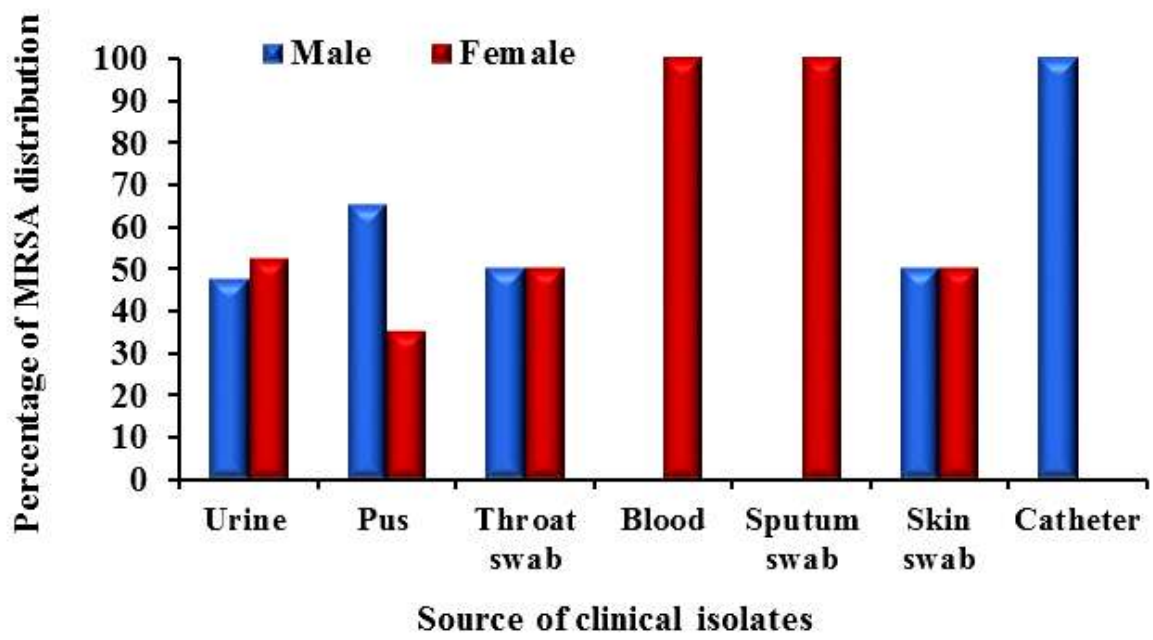

Fig. (4): Percentage of MRSA distribution in clinical sources by gender. 
Antibiotics susceptibility of MRSA isolates

All MRSA isolates were resistance to amoxicillin and cefuroxime. Higher resistance for clarithromycin, erythromycin, imipenem, meropenem (78.6\%), amikacin, tobramycin $(77.1 \%)$, chloramphenicol, ciprofloxacin, ofloxacin $(74.3 \%)$, tetracycline $(71.4 \%)$ and clindamycin $(62.8 \%)$. Only $50 \%$ of the isolates were sensitive to vancomycin (Fig. $5)$.

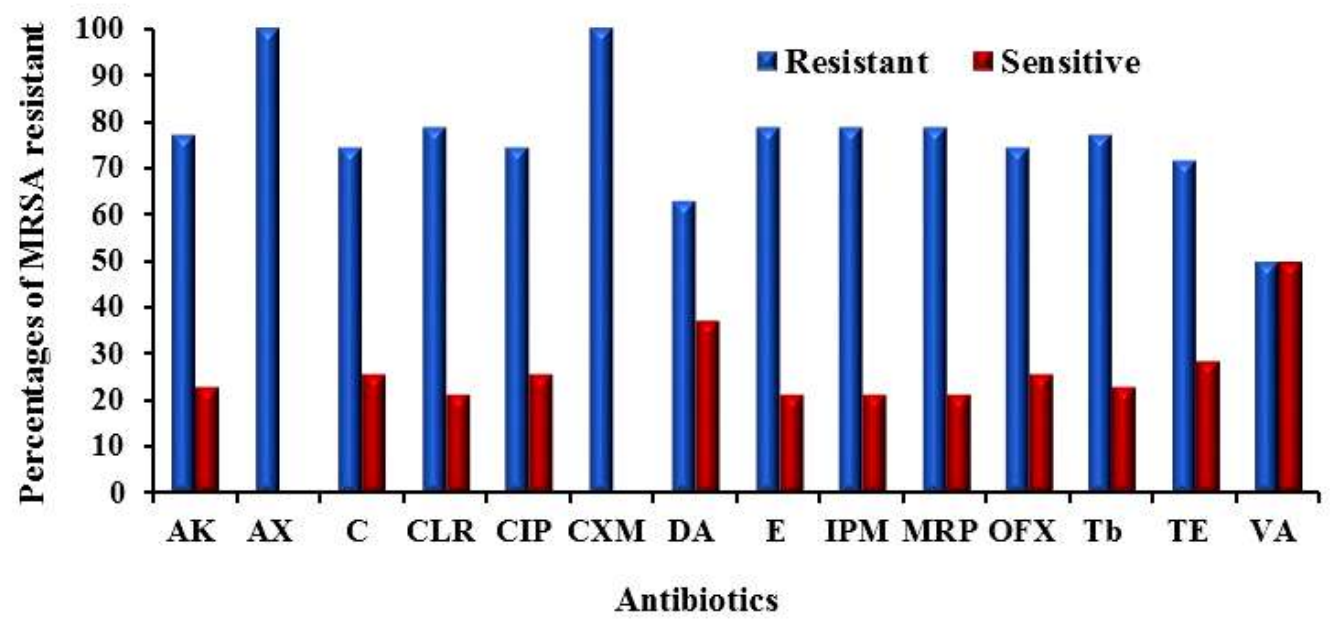

Fig. (5): Antibiotic sensitivity test of MRSA isolates.

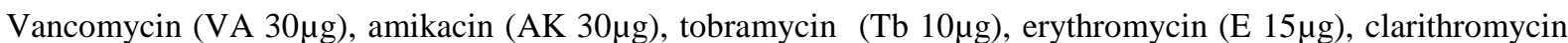
(CLR $15 \mu \mathrm{g}$ ), amoxicillin (AX $25 \mu \mathrm{g}$ ), clindamycin (DA $2 \mu \mathrm{g}$ ), chloramphenicol (C $30 \mu \mathrm{g}$ ), meropenem (MRP $10 \mu \mathrm{g}$ ), imipenem (IPM $10 \mu \mathrm{g}$ ), cefuroxime (CXM $30 \mu \mathrm{g}$ ), ciprofloxacin (CIP $5 \mu \mathrm{g}$ ), ofloxacin (OFX $5 \mu \mathrm{g}$ ), tetracycline (TE $30 \mu \mathrm{g})$.

Determination of minimum inhibitory concentration (MIC) of oxacillin According to MIC, all MRSA isolates were resistant to $4 \mu \mathrm{g} / \mathrm{ml}$ oxacillin. Higher MIC $(256 \mu \mathrm{g} / \mathrm{ml})$ was detected in
$12.9 \%$ of MRSA isolates, while lower one $(8 \mu \mathrm{g} / \mathrm{ml})$ was observed in $21.4 \%$ of the isolates (Fig. 6).

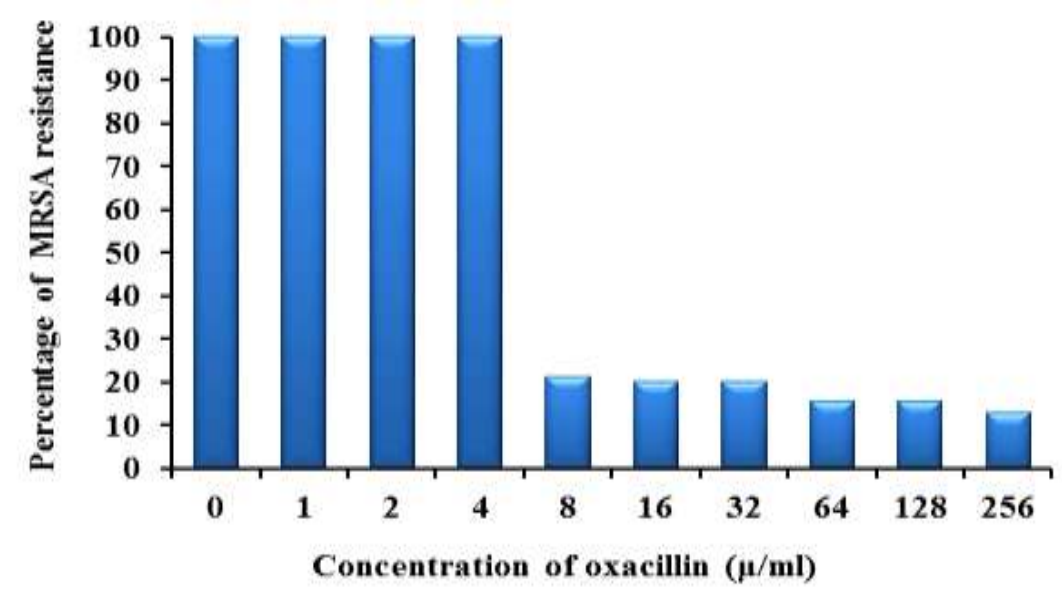

Fig. (6). Minimum inhibitory concentration (MIC) of MRSA against oxacillin. 
Eman S.H. Ibrahim et al.

\section{DISCUSSION}

Staphylococcus aureus is a common opportunistic bacterium which is an important pathogen due to combination of toxin-mediated virulence, invasiveness, and antibiotic resistance (Qiu et al., 2010). Previously, $S$. aureus infections were primarily treated with $\beta$-lactam antibiotics, including oxacillin, a second-generation penicillin. Soon after the emergence of MRSA, these early generation $\beta$-lactam antibiotics were eliminated from the treatment options. To date according to Miller et al., (2020), MRSA has become one of the most prevalent multi-drug resistant pathogens, and is responsible for most nosocomial and community-acquired infections worldwide (Tong et al., 2015; Stryjewski and Corey, 2014). In this study, the percentage of identified MRSA isolates among $258 \mathrm{~S}$. aureus clinical isolates was $27 \%$. This finding agreed with previous surveillance study carried out to measure the resistance in $S$. aureus and revealed the presence of methicillin resistance in 32\% of $S$. aureus isolates (Udo et al., 2008).The present study showed that the percentage of agreement between susceptibility to both Cefoxitin $(30 \mu \mathrm{g})$ and oxacillin $(1 \mu \mathrm{g})$ antibiotics and culturing on selective ORSAB medium for detection and identification of MRSA was $100 \%$. These results agreed with Zeeshan et al (2007) and Stoakes et al. (2006) who used these phenotypic methods for better sensitivity to MRSA identification. However, other studies reported that growing on ORSAB for $48 \mathrm{~h}$ showed $98 \%$ sensitivity (Becker $e t$ al., 2002) and 96\% sensitivity (Nguyen Van et al., 2006; Nsira et al., 2006).

In this work, higher MRSA isolates were observed in females compared with males in most of the clinical samples. This was congruent with Terry Alli et al. (2012) who found that MRSA was prevalent among female patients.

In the present study, the highest MRSA isolates were recovered from pus $(57.1 \%)$. This higher frequency of MRSA in pus specimen has been previously reported especially in diabetic foot infections, surgical wounds, and burn patients (Garoy et al., 2019). On the other hand, the higher MRSA isolates recovered from the investigated urine clinical samples agreed with the studies of Akortha et al. (2008) and Aboderin et al. (2009) who reported increasing prevalence of Staphylococcus aureus in urinary tract infection. The presence of MRSA in a urine culture has important consequences for patients, both in the community and the hospital setting. MRSA in urine clearly warrants treatment in symptomatic patients, but even in asymptomatic patients, it may require eradication before certain elective procedures such as endourological surgery (Looney et al., 2017). No MRSA isolates were detected in prostatic fluid which was incongruent with Carroll et al. (2017) who reported 26 staphylococcal prostatic abscesses caused by MRSA.

In the present study, the antibiotic susceptibility revealed that all MRSA isolates were resistance to amoxicillin and cefuroxime. In addition, $78.6 \%$ of MRSA isolates were resistant to clarithromycin, erythromycin, imipenem, meropenem. Similar results were reported by Prakash et al. (2007). Only $50 \%$ of the isolates were sensitive to vancomycin which is regarded as the drug for treatment of infections caused by MRSA. However, emergence of vancomycin resistant Staphylococcus aureus has been reported by Kshetry et al. (2016). Higher MICs for MRSA isolates were detected in this study which indicated that the phenomena of multiple drug resistance in MRSA became more and more serious.

\section{Conclusion}

MRSA isolates from different clinical sources showed high prevalence in pus followed by urine. All MRSA were resistant to amoxicillin and cefuroxime and $50 \%$ to vancomycin. Higher concentration 
of oxacillin $(256 \mu \mathrm{g} / \mathrm{ml})$ was needed to inhibit the growth of $12.9 \%$ of MRSA isolates.

\section{REFERENCES}

Aboderin, O.A.; Abdu A.R.; Odetoyin B.W. and Lamikanra, A. (2009). Antimicrobial resistance in Escherichia coli strains from urinary tract infections. J. Natl. Med. Assoc., 101: 1268-1273.

Akortha, E.E. and Ibadin, O.K. (2008). Incidence and antibiotic susceptibility pattern of Staphylococcus aureus amongst patients with urinary tract infection (UTIS) in UBTH Benin City, Nigeria. Afr. J. Biotechnol., 7: 637640.

Baired-Parker, A.C. (1962). An improved diagnostic and selective medium for isolating coagulase-positive staphylococci. J. App. Bacteriol., 25:12-19.

Bannerman, T.L. (2003). Staphylococcus, Micrococcus, and other catalasepositive cocci that grow aerobically. In: Murray, P.R.; Baron E.J.; Jorgensen J.H.; Pfaller M.A. and Yolken R.H. (ed.). Manual of clinical microbiology, $8^{\text {th }}$ Ed. American Society for Microbiology, Washington, D.C.

Becker, A.; Forster, D.H. and Kniehl, E. (2002). Oxacillin resistance screening agar base for detection of methicillin-resistant

Staphylococcus aureus. J. Clin. Microbiol., 40:4400-4401.

Boswihi, S.S. and Udo, E.E. (2018). Methicillin-resistant

Staphylococcus aureus: an update on the epidemiology, treatment options and infection control. Curr. Med. Res. Pract., 8:18-24.

Boyce, J.M.; Nancy, L. and Havill, M.T. (2004). Do infection control measures work for methicillin-resistant
Staphylococcus aureus? Infect. Control Hosp. Epidemiol., 25: 395-401.

Boyd, E.F. and Brüssow, H. (2002). Common themes among bacteriophage-encoded virulence factors and diversity among the bacteriophages involved. TRENDS Microbiol., 10:521-529.

Carroll, D.E.; Marr, I.; Huang, G.K.L.; Holt, D.C.; Tong, S.Y.C. and Boutlis, C.S. (2017). Staphylococcus aureus prostatic abscess: a clinical case report and a review of the literature. BMC Infect. Dis., 17:509.

Cepeda, J.A.; Whitehouse, T.; Cooper, B.; Hails, J.; Jones, K.; Kwaku, F.; Taylor, L.; Hayman, S.; Cookson, B.; Shaw, S.; Kibbler, C.; Singer, M.; Bellingan, G. and Wilson, A.P.R. (2005). Isolation of patients in single rooms or cohorts to reduce spread of MRSA in intensive-care units: prospective two-centred study. Lancet, 365: 295-304.

Chambers, H.F. (2001). The changing epidemiology of Staphylococcus aureus. Emer. Infect. Dis.,7:17882.

Clinical and Laboratory Standards Institute (CLSI), (2017). Performance Standards for Antimicrobial Disc Susceptibility Tests.

Cutler, R.R. and Wilson, P. (2004). Antibacterial activity of a new, stable, aqueous extract of allicin against methicillin-resistant Staphylococcus aureus. British J. Bio. Sci., 61:71-74.

EUCAST (2000). EUCAST Definitive Document E.DEF 3.1, June 2000: Determination of minimum inhibitory concentrations (MICs) of antibacterial agents by agar dilution. Clin. Microbial. Infect., 6:509-515.

Garoy, E.Y.; Gebreab, Y.B.; Achila, O.O.; Tekeste, D.G.; Kesete, R.; 
Eman S.H. Ibrahim et al.

Ghirmay, R.; Kiflay, R. and Tesfu, T. (2019). Methicillin-resistant Staphylococcus aureus (MRSA): prevalence and antimicrobial sensitivity pattern among patients-a multicenter study in Asmara, Eritrea. Can. J. Infect. Dis. Med. Microbiol., 2019:1-9.

Hancock, R.E.W. (2007). The end of anera? Nat. Rev. Drug Discov.,6:28.

Hayani, K.C.; Roshni, M. and Oyedele, T. (2008). Neonatal necrotizing fasciitis due to communityacquired methicillin resistant Staphylococcus aureus. J. Ped. Infec. Dis., 27:480-481.

Isenberg, H.D. (1992). Clinical Microbiology Procedures Handbook. American Society for Microbiology, Washington, D.C.

Kloos, W. E. and Schleifer, K. H. (1986). Staphylococcus Rosenbach 1984. In: P.H.A. Sneath, et al., Bergey's manual of systematic bacteriology, 2: 1013-1019. The Williams and Wilkins Co., Baltimore, MD.

Kluytmans, J.; van Belkum, A. and Verbrugh, H. (1997). Nasal carriage of Staphylococcus aureus: epidemiology, underlying mechanisms, and associated risks. J. Clin. Microbiol. Rev.,10:505520.

Kluytmans, J.; Griethuysen, A.V. and Willems, S. (2002). Performance of CHROM agar selective medium and oxacillin resistance screening agar base for identifying Staphylococcus aureus and detecting methicillin resistance. J. Clin. Microbiol., 40:2480-2482.

Koneman's color atlas (1992). Textbook of diagnostic microbiology by Washington C., Winn, Elmer W. and Koneman P. 987.

Kshetry, A.O.; Pant, N.D.; Bhandari, R.; Khatri, S.; Shrestha, K.L.; Upadhaya, S.K.; Poudel, A.; Lekhak, B. and Raghubanshi,
B.R3. (2016). Minimum inhibitory concentration of vancomycin to methicillin resistant Staphylococcus aureus isolated from different clinical samples at a tertiary care hospital in Nepal. Antimicrob. Resist. Infect. Control, 5: 27.

Lake, J.G.; Weiner, L.M.; Milstone, A.M.; Saiman, L.; Magill, S.S. and See, I. (2018). Pathogen distribution and antimicrobial resistance among pediatric healthcare-associated infections reported to the national healthcare safety network, 2011-2014. Infect. Control Hosp. Epidemiol.,1:1-11.

Looney, A.T.; Redmond, E.J.; Davey, N.M.; Daly, P.J.; Troy, C.; Carey, B.F. and Cullen, I.M. (2017). Methicillin-resistant

Staphylococcus aureus as a uropathogen in an Irish setting. Medicine (Baltimore), 96: e4635.

Lowy, F.D. (1998). Staphylococcus aureus infections. New Eng. J. Med., 339:520-532.

Mera, R.M.; Suaya, J.A.; Amrine-Madsen H. et al. (2011). Increasing role of Staphylococcus aureus and community-acquired methicillinresistant Staphylococcus aureus infections in the United States: a 10-year trend of replacement and expansion. Microb. Drug Resist., 17:321-328.

Mims, C.; Dockrell, H.M. and Goering, R.V. (2004). Medical Microbiology, $3^{\text {rd }}$ edition, Elsevier Mosby, Edinburgh, United Kingdom: 585-586.

Moorem, P.C.L. and Lindsay, J.A. (2001). Genetic variation among hospital isolates of methicillin-sensitive Staphylococcus aureus: evidence for horizontal transfer of virulence genes. J. Clin. Microbiol., 39:2767.

Murray, P.R.; Baron, E.J.; Pfaller, M.A.; Tenover, F.C. and Yolken, R.H. (1999). Manual of clinical 
microbiology Washington, DC: American Society for Microbiology Press $7^{\text {th }}$ ed.

NCCLS (2017). Antimicrobial susceptibility testing. National Committee for Clinical Laboratory Standards.

Nguyen Van, J.C.; Kitzis, M.D.; Ly, A.; Chalfine, A.; Carlet, J.; Ben Ali, A. and Goldstein, F. (2006). Detection of nasal colonization MRSA: a prospective study comparing realtime genetic amplification assay vs selective chromogenic media. Pathol. Biol., 54:285-292.

Nsira, S.B.; Dupuis, M. and Leclercq, R. (2006). Evaluation of MRSA Select, a new chromogenic medium for the detection of nasal carriage of methicillin- resistant Staphylococcus aureus. Int. J. Antimicrob. Agents, 27: 561-564.

Panlilio, A.L.; Culver, D.H.; Gaynes, R.P.; Banerjee, S.; Henderson, S.; Tolson, J.S and Martone, W.J. (1992). Methicillinresistant Staphylococcus aureus in U.S. hospitals, 1975-1991. Infect. Control Hosp. Epidemiol.,13:582586.

Prakash, M.; Rajasekar, K. and Karmegam, N. (2007). Prevalence of methicillin resistant Staphylococcus aureus in clinical samples collected from Kanchipuram Town, Tamil Nadu, South India. J. Appl. Sci. Res., 3:1705-1709.

Qiu, J.; Feng, H.; Lu, J.; Xiang, H.; Wang, D.; Dong, J.; Wang, J.; Wang, X.; Liu, J. and Deng, X. (2010). Eugenol reduces the expression of virulence-related exoproteins in Staphylococcus aureus. Appl. Environ. Microbiol., 76: 58465851.

Stoakes, L.; Reyes, R.; Daniel, J.; Lennox G.; John, M.A.; Lannigan, R. and Hussain, Z. (2006). Prospective comparison of a new chromogenic medium, MRSA Select, to CHROM agar MRSA and mannitol-salt medium supplemented with oxacillin or cefoxitin for detection of MRSA. J. Clin. Microbiol., 44:637-639.

Stryjewski, M.E. and Corey, G.R. (2014). Methicillin-resistant

Staphylococcus aureus: an evolving pathogen. Clin. Infect. Dis., 58:S10-9.

Terry Alli, O.A.; Ogbolu, D.O.; Mustapha, J.O.; Akinbami, R. and Ajayi, A.O. (2012). The nonassociation of Panton-Valentine leukocidin and mecA genes in the genome of Staphylococcus aureus from hospitals in South Western Nigeria. Indian J. Med. Microbiol., 30:159-164.

Tong, S.Y.; Davis, J.S.; Eichenberger, E.; Holland, T.L. and Fowler, V.G.Jr. (2015). Staphylococcus aureus infections: epidemiology, pathophysiology, clinical manifestations, and management. Clin. Microbiol. Rev., 28:603-661.

Udo, E.E.; Al-Sweih, N.; Dhar, R.; Dimitrov, T.S.; Mokaddas, E.M.; Johny, M.; Al-Obaid, I.A.; Gomaa, H.H.; Mobasher, L.A.; Rotimi, V.O. and Al-Asar, A. (2008). Surveillance of antibacterial resistance in Staphylococcus aureus isolated in Kuwaiti hospitals. Med. Prin. Prac., 17:7175.

Zeeshan, M.; Jabeen, K.; Khan, E.; Irfan, S.; Ibrahim, S.; Parween, Z. and Zafar, A. (2007). Comparison of different phenotypic methods of detection of methicillin resistance in Staphylococcus aureus with the molecular detection of mecA gene. J. Coll. Physicians Surg. Pak., 17:666-670. 
إنتشار مقاومة الأدوية المتعددة في عزلات المكورات العنقودية الذهبية المقاومة للميثيسيلين

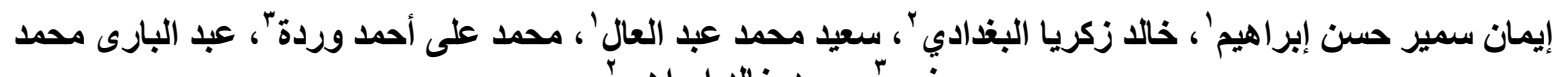

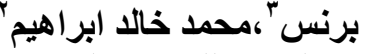

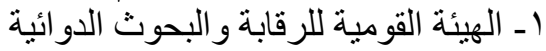

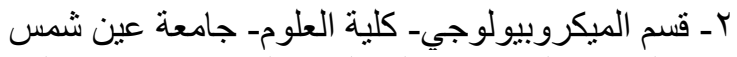

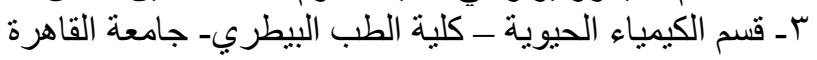

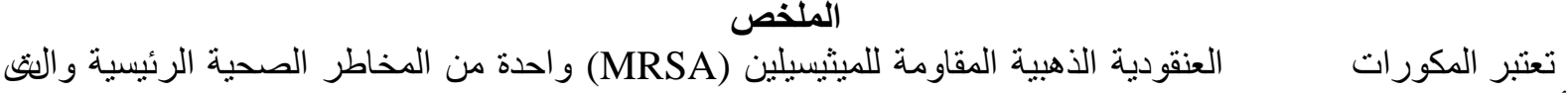

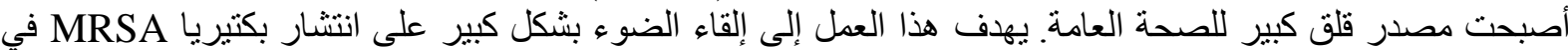

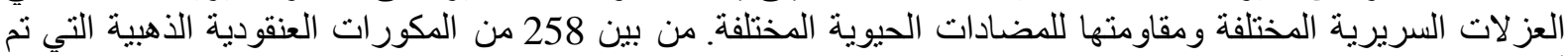

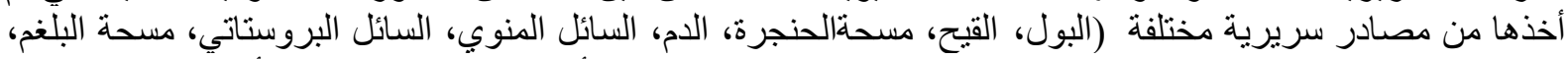

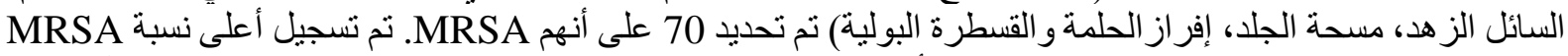

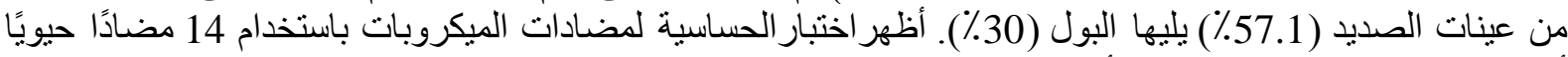

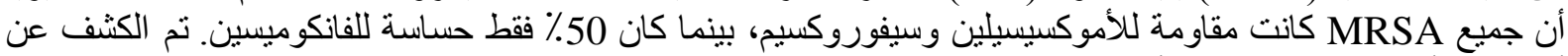

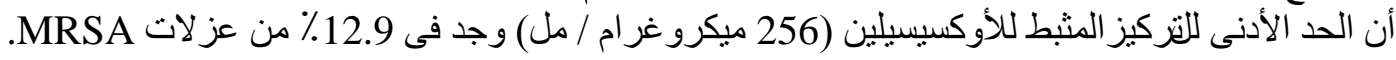

